\title{
Applying DBA Research Concepts In Attending Any UAE Based SME Challenges Post Covid 19 And Global Market Slowdown
}

\author{
Hussein Salloum \\ Dynergy Technologies
}

\begin{abstract}
This report discusses how a dba degree would enable investigate evolving types of leadership styles that small and medium enterprises, particularly in manufacturing sector in united arab emirates develop since the outbreak of covid-19 pandemic on multiple levels of strategies, financial, human resource, as well as health and safety. The study considers the management research concepts and methodologies in one case of one dubai based sme firms amid year 2020 pandemic challenges. It draws a roadmap for the research process, and formulates the plan to conduct purposeful and demanding topic from an ethical and business perspective that would have similar effects on similar smes in the region
\end{abstract}

\section{Introduction.}

Doctorate in business administration is becoming an increasingly required degree in the field of postgraduate academic studies due to its importance in analyzing and attending practical problems in the field of real life organizations. While PHD degrees focus on highest levels of theoretical approach toward the field of study, DBA approaches the development and professional practice of definite companies or specific manager.

Challenges and decision making process at senior management levels are widening and becoming more complex with a fast pace changing world. Global economy interrelations are exponentially increasing due to the fast technological and logistical advancement, and corporates budget sizes are reaching astronomical figures that have outturned government volumes and penetrated across continents. In addition, environmental and ethical requirements are adding up to the responsibilities of decision makers in every organization strategy and policy.

Covid 19 represents the most recent and imminent challenge that entities and managers are facing since Dec 2019. While this outbreak has affected mega size corporates in various degrees, it has affected mostly small and medium size enterprises all over the globe. UAE have been one of the economies where SMEs witnessed stressful consequences, despite the government stimulus packages that have been and still being released on multiple stages since March 2020.

The study approaches one/any Dubai based SME to apply the DBA concepts, theories, and methodologies to analyze and attend the senior management organizational concerns. It conceptualizes the research, defines the subject focus field, identifies the organizational problem, designs a research question, and provides the stages which this research should undergo, considering the ethical perspective.

\section{Section 1}

\section{Conceptualizing Management Research}

\section{Relation to Social Sciences}

Social sciences are classified into categories such as psychology, sociology, and economics. Scientific research has two types: inductive and deductive. Inductive research uses the observed data to reach a theory while inductive tests concepts and theories through observed empirical data. Construction and testing of theory are not easy task due to the non-conclusive nature of concepts and due to many factors that could be unaccounted for during course of research. Unlike natural sciences, social sciences theories are not decisive and thus provide room for improvement of its theories. Scientific research requires two skills, theoretical and methodological. While methodologies are easier to master, theoretical skills in management research requires years of experience and observation in order to be formulated (Bhattacherjee, 2012).

\section{Theories}


Theories can be classified on various grounds in relation to its historical development with the industrial and technological developments (classical to modern) and by type (normative, analytic, and descriptive).

Koontz (1961) classified the management theories into six groups: management, empirical, human behavioural, social systems, decision, and mathematical schools of thoughts. However, Middle Mist, R Dennis and Mathis, Robert L. (1979) classification was summarized into classical schools, neoclassical, and modern management.

\section{Classical Schools}

Classical Theory was formulated in nineteen and twentieth century and had been greatly affected by the rising manufacturing development in the industries during this period. It showed clear structure for management, division of labour and responsibilities of employees. However, it have bypassed the humanistic creativity and showed more focus in experience.

Frederick W. Taylor had developed the scientific management theory which revolved around the division of work, training of workers, and specialization in addition to tangible incentives. It was based on four principles: scientific management, systemic recruitment, education and development of labour, friendly cooperation. (Taylor, 1911)

Henri Fayol investigated the managerial behaviour and development 14 principles that are division of work, authority, discipline, unity of command, unity of direction, subordination to common good, remuneration, centralization, hierarchy, order, equity, stability, initiative, and team spirit. (Fayol, 1917)

\section{Human Relations Theory}

This theory focused on the need to achieve job satisfaction, and that workers should be given meaningful work, with managers recognizing staff and facilitation of their development in the workplace. Like economical incentives, psychological needs motivate employees for better efficiency in productivities (Mayo, 1933). McGregor (1960) described that human relations concept was limited to addressing people's needs while it needed to address satisfactions and strategies for better productivity.

It is clear that human relation school have developed deviation from the scientific and classical schools that the employee was a machine-like parameter who responds only to monetary incentives. (Ajayi and Ayodele, 2011)

\section{Decision Theory}

Decision Theory emerged in 1950s and is based on studying the agents' choices and determining the best decision, and its empirical applications follow econometric methods and statistics. James G March (born 1928) have analysed the human behavioural and decision making process using mathematical based models. (Cyert and March, 1963)

\section{Work Activity Theory}

Theorists of work activity have seen management as an activity to set objectives, organize, motivate, measure and develop skills. Management target is to empower people for joint performance towards common goals, values, structure, and to train them to perform and to respond to change. (Greenwood, 2002)

\section{Competencies Theory}

Human resource practices in 1980s have played important role to develop competencies theory that is often applied in organizations to guide selection, assessment, development, and performance appraisal. Further to global economic crisis, competency management is widely used for selection purposes and for performance appraisal (Heinsman, 2006). Strengths and weaknesses are used as criteria for performance appraisal. The aim had been to reduce costs, improve standards to be able to stand for the growing competition and to increase effectiveness. After all, managers use competency management mainly to organize or control the workforce.

\section{Critical Theory}

It has evolved in the end of last century in response to critical thinking approach towards many theories set by then. It digs in deeper layers of power games and calls for social benefits and more sustainable policies. Postmodernism has many writers and research agendas, where they focus on people and reality and argues against large sale theories such as Marxism and Functionalism. (SAGE Publications, 2006) 


\section{Road Map to Management Research}

Further to the above speeding evolution of theories, and based on the academic basis of conceptualizing of any type of scientific research, we can define management research as a critical yet objective investigation for a specific business problem where the subject research aim is to provide the systematic solution for it.

With twenty first century technologies and advanced digitalization of several aspects in business communities, management research becomes a desirable and imminent need to attend firms' challenges and dilemmas. Each problem will have its unique circumstances and influential elements, thus pressing the need to systemize the question and its answer through such research. Some theories might apply on one case whereas another would not.

In an extremely fast paced financial world order, firms regularly face strategic and major as well as situational or minor challenges that need to be tackled on immediate and longer term basis. Once research is conducted and concluded, it will be the manager call at the end to embrace the conclusion and execute. This imposes responsibilities on researchers and managers to cooperate and know the risks and ethical background at both sides. This collaboration plays a decisive role in success or failure of the organization.

\section{Section 2}

\section{Leadership And Organizational Change - Convergence Towards Global And Crisis Leadership Styles}

This section discusses leadership and organizational change as interrelated topics. They gained increasing importance within organizations due to the rapidly changing circumstances and continuous major global challenges that put these concepts as the tip of the sword in leading and attending these challenges. These rapid developments have given rise to new types of leaderships such as global and crisis leadership styles.

\section{Leadership Concepts Developments}

Leadership plays an essential part in motivating people towards a common goal. It is usually shown through using certain skills and traits that are inbuilt or acquired by the manager. Concept of a business leader has been evolving for the past decades in relation to development of management research over the past two centuries, where several types of leadership have been identified, some are classical like transformational and transactional theories (Burns, 1978), and some are recent like global leadership (Doty \& Glick, 1994).

\section{Classical Theories for Leaderships}

Classical leadership types (transformational and transactional) were developed by Burns (1978) and Bass (1985) using productive and progressive theories to define the relation between the managers and subordinates. Burns (1978) considers leadership from a political perspective, while Bass (1990) inspired by Burns, established the widely dominant theory of leadership. .

Transformational leadership roots deep in the personal morals and values of the manager, such as fairness, integrity, and equality. This type leads to achievement of better performance among employees. (Bass, 1985). Charisma plays an essential role with such type in addition to self-confidence, control, strong persuasion, and righteous beliefs. This "Physical Charisma" trait is getting replaced gradually by the "Digital Charisma" as firms become more digitized and where communication and interaction take place in the virtual world more than in real one. This is giving rise towards digital identity importance hence opening more doors towards in depth research about digital leadership.

Transactional leadership on other hand is derived from the exchanges where the leader and follower affect each other mutually so that each derives something of value (Yuki, 1981). This creates back and forth dependence in which both sides are rewarded (Kellerman, 1984). Exchanges in such types are mostly not equivalent and are divided into high-quality and low-quality relations, where high-quality focuses on emotional non-concrete rewards and low-quality relates to tangible rewards such as bonuses and monetary benefits (Yuki, 1981). In fact, transactions that were investigated during "Industrial Revolution" would be different from ones being investigated now in the age of "Stock Markets". An employee might not want a cash bonus but rather a stock share in the company.

These two types of leadership depend mainly on the personality variables. As such, constructive/developmental personality theory plays a major role in providing a model for investigating the methods through which such types of leadership develop (Kegan, 1982). The constructive segment of this considers that humans have subjective perspective of the outside environment and this shapes their concepts 
of real world. Kegan (1982) provided six developmental stages: incorporative, impulsive, imperial, interpersonal, institutional, and interindividual as shown in the figure below.

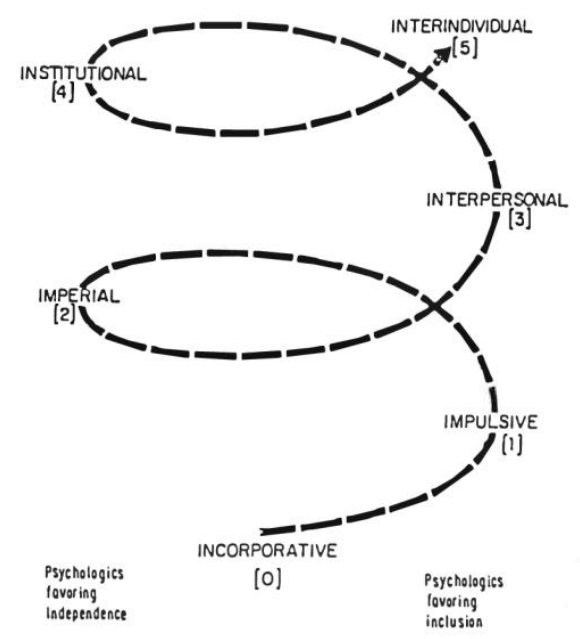

Figure 2.1 Kegan Six Developmental Stages

Incorporative stage involves sensorimotor skills and serves as pre-social level. Impulsive stage involves the family triangle and pre-operational levels. Leadership starts on imperial stage in which inferior level techniques of transactional leadership are involved such as team spirit and mutual respect, yet without having the organizing skills to participate in shared experience or perceptions, like aiming to be the youngest manager in the business unit. However, this when individual reach Interpersonal stage as per Kegan (1982), personal needs are superseded, after which the leader sacrifice the personal goals for the sake of their subordinates, thus elevating to a higher level of transactional leadership. Moving up to Institutional stage means the leader has crossed the conflict of maintaining the locality of organization and the subordinates, by developing a frame of organizational reference and creation of what Burns (1978) calls the end values. Such leaders are defined as transformational, where they show maturity, critical thinking, integrity, self-respect, equality, and they evaluate their own performances.

Later on Kegan and Lahey (2009) described in their book, Immunity to Change, three dimensions of intolerance to change: the change-preventing system, the feeling system, and the knowing system. They conduct number of actual studies and formulate three types of mindsets: socialized mind, self-authoring mind, and self-transforming mind as shown in the figure below.

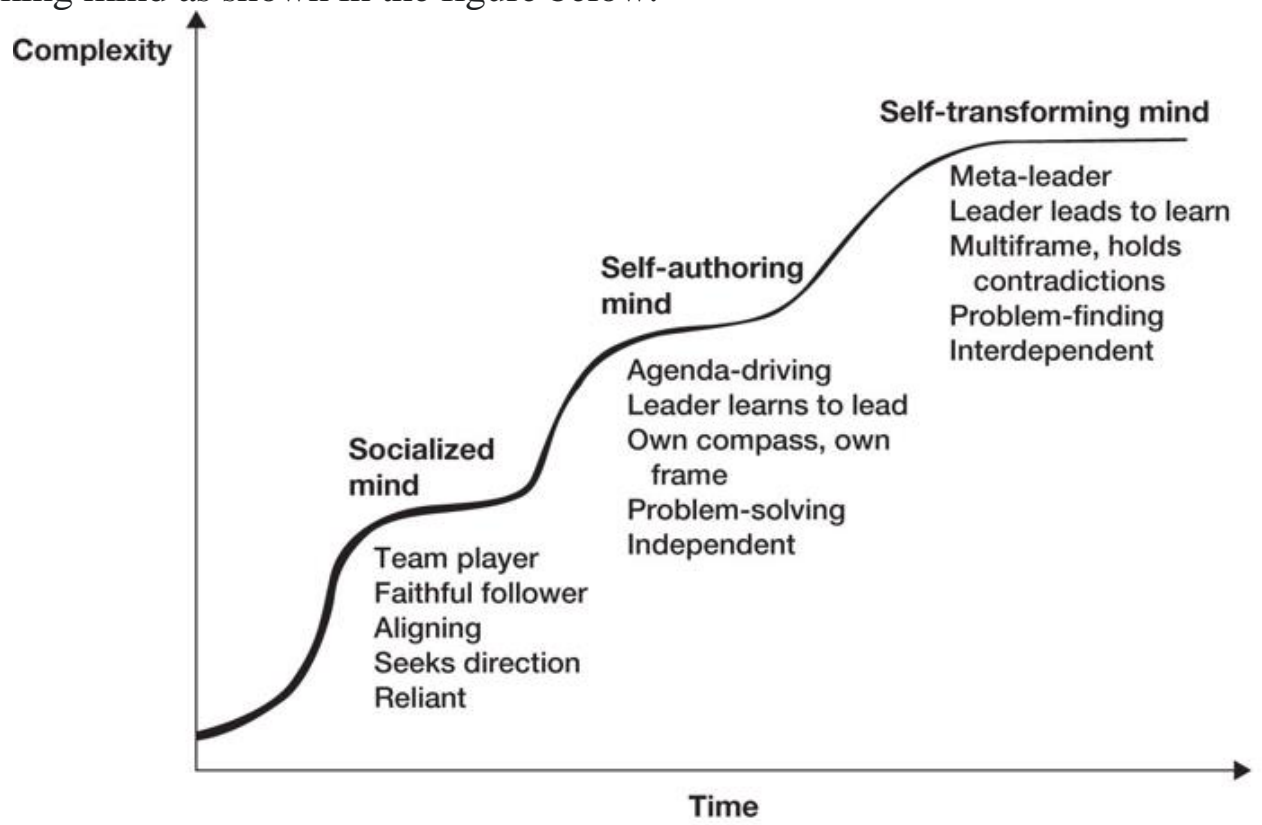

Figure 2.2 Three mindsets of Human Development, Kegan and Lahey (2009)

Socialized mind individuals are decent team players and truthful followers, but their words and actions are strongly influenced by what they believe others desire. Self-authoring individuals are determined and selfdirected. They are effective in management; but sometime they have difficulty in detecting the changes, restructuring their situation, and changing their strategies. Self-transforming mind individuals are capable of 
assessing their own assumptions and reforming their perspectives as needed. They handle complex challenges, support transformation whether individual or organizational (Rooke and Torbert, 1998, 2005; Torbert, 2006) and show high competence in managing conflicts, solving problems, delegating, and empowerment. (Kegan and Lahey, 2009)

\section{Evolving Theories for Leaderships in the rise of globalization and pandemics}

Globalization has been a rapid process in the last thirty years further to the Berlin Wall Fall in 1989 and the vast development of the telecommunication technologies. There has been an exponential leap in digital economies since 2004 with the emergence of social and professional digital platforms and artificial intelligence. In addition, for the last two decades, the human kind experienced multiple serious pandemics, the last which was COVID 19 outbreak in Dec 2019. Warren Bennis (2007) theorized that there is couple of major threats to world stability that were affecting leadership in the context of rising globalization and pandemics.

\section{A. Global Leadership Theory - Cross Cultural Transformational Leaders}

Global leadership is the actions and processes that a manager influences internal and external elements from multi-national diversities thus have context as a key emergency factor (Doty \& Glick, 1994) which distinguishes typical global leadership roles. While research on global leadership is fast growing and diverse, the global leadership construct is conceptually underdeveloped and theories of global leadership remain rare (Osland et al., 2014). Gibson and McDaniel (2010) suggested the reconceptualization of leadership theories to include cross-culturalism due to lack of cross-cultural experience many organization need.

Cross-cultural leadership necessitates leading in a multi- cultural environment (Caligiuri, 2013). It is now commonly found in many organizations a group of people with diverse values, background, morals, laws, and ethnicities as shaped by their societal circumstances. Cross-cultural leaders thus look to embrace the diversity of all stakeholders.

This style combined with transformational leadership is increasing gaining significance to be an effective style to counter the challenges of globalized organizations. Mixed with enhanced skills and effective sharing of information, the global leadership style constitutes the promising style that would determine the sustainability, performance, and innovative culture of business entities.

Cross cultural transformational leadership style has multiple characteristics that can be bulleted as below:

- Culturally sensitive: means valuing and accepting the practices of people from different ethnics, regions, or religions. Sohn (2015) noticed that a cross cultural leader is culturally sensitive and knowledgeable about cultures of other people. Reynolds (2017) noticed that South Korea and China prefer use of Mr. or Miss followed by a person's last name as the correct way addressing people whereas United States people address directly by their first names. Emotional Intelligence plays essential role in development of such skills.

- Open Minded: shows the ability to accept and learn about other cultures and beliefs, thus digesting the reasons of having certain ways of life. This is essential whenever working and leading for expats in abroad countries where social awareness is needed to be creative and innovative towards meeting new customers' demands. MacDonald's food menu have been altered to local tastes in several countries around the world, where for example more spices are added for food meals in India, and where "halal" note is provided is some Islamic countries for chicken and meat packages.

- Culturally Knowledgeable: knowing the habits and cultural origins of employees means positioning them in the right places and giving them the properly suitable tasks for such background. Individualistic and collectivistic cultures vary between western and eastern societies, same for north and south. Also, whereas family -work time balance is sacred in countries like Japan (Reynolds, 2017) and lead to maximizing potentials, an Indian employee lean more towards paternalistic leader Pellegrini et al. (2010).

\section{Cross cultural employees and customers}

In addition to normal criteria of skills and experience, employees with cross-cultural features are preferred by leaders (Zoogah \& Abbey, 2010). Those employees show more self-motivation and have more independency that is needed for change and rising up the organizational performance. On the other hand, the 
gobal customer base is expanding in increasing rates, and thus leaders are adjusting their products more towards taste preference like what Starbucks did in Asia where tea is the preferred drink rather than coffee.

\section{Organizational Creativity}

Innovation is entering into new and unpredictable territory (Pisano, 2019). Global organizations are continuously looking for new customers and making new products. This makes cross-cultural employees and leaders strategic. Different backgrounds may present learning opportunities in the organization where a transformational leader motivate individuals to increase innovation thus development of the organization.

\section{B. Shock Leadership Development}

It is the need for exceptional competences in crisis leadership where crisis management is alarmed with the before, now, and after. It indicates that planning as well elements of developing leadership and active measures are necessary (Herbane, 2013; James, 2011). It is known that many managers and organizational leaders face unprecedented environments that are extremely uncertain and chaotic with fast changing needs like COVID-19

Pandemic outbreak, this does not mean that it is not possible to enable them to be equipped and proactive towards effective reactivity. This is similar to how you prepare a military officer to combat situation where extreme and unfavorable scenarios are simulated over and over again till they acquire the skills and know how to counter these abnormalities with least causalities possible.

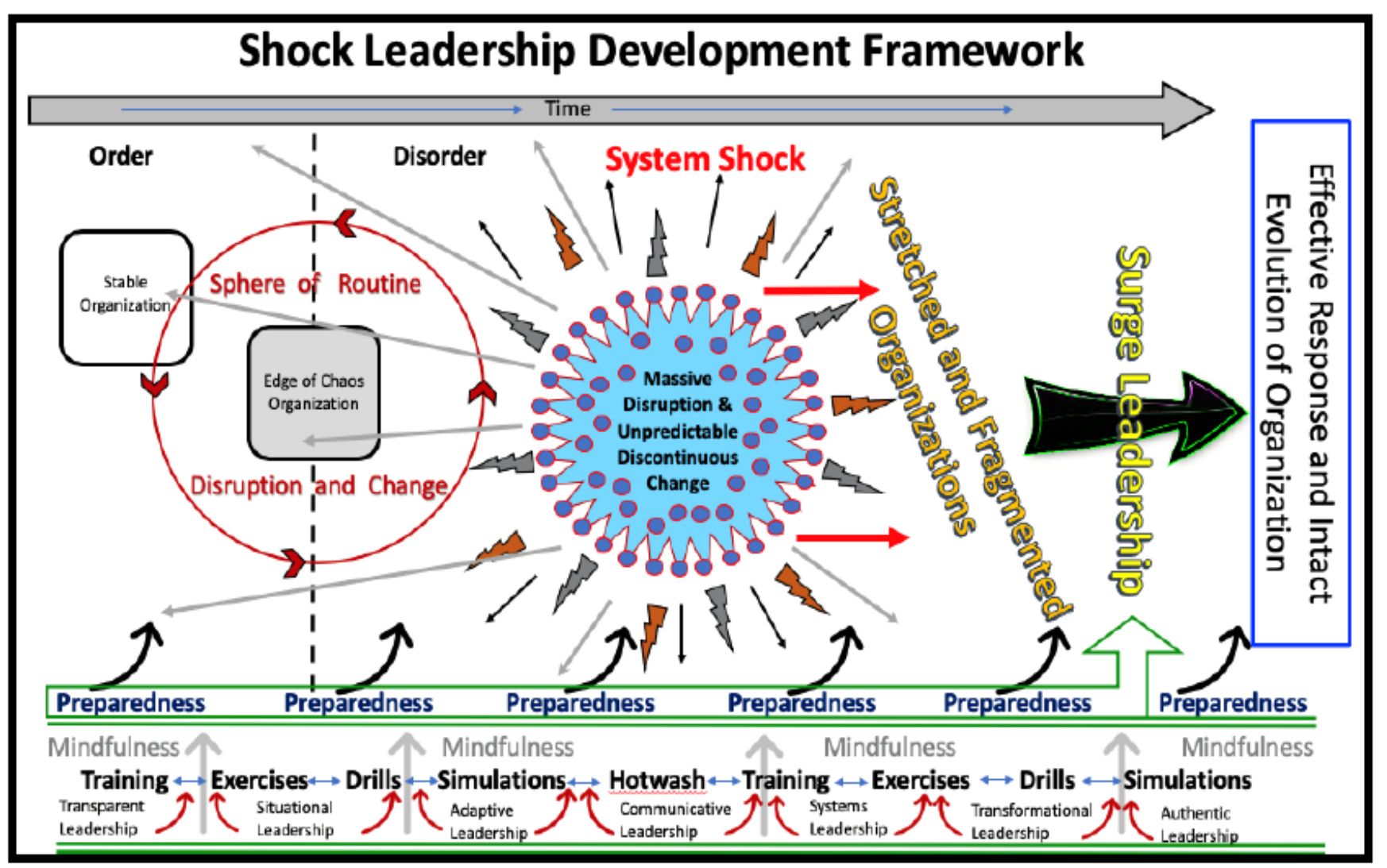

Figure 2.3 Shock Leadership and Preparedness Model

By integrating multiple leadership styles and muddling them to arising situations, the surge leader is able to respond effectively to destabilizing conditions that shakes the organizational systems. This knowledge and skills is attained along with practice of real-time scenario-based training and enables leaders to employ different leadership styles, as necessary in different scenarios. As such, Shock Leadership Development implementation gives chance for testing and learning effective crisis communication as a vigorous part to effective group dynamics, exchanges, and for stirring and transforming people (Lvina, 2014; Men, 2014a; Men, 2014b). 


\section{Section 3}

\section{Organizational Problem In Dubai Based Manufacturing SME}

\section{Identifying the Problem}

DBS (Dubai Based SME) is the abbreviation to refer on the selected company for study to serve confidentiality until we receive the consent from the related owners for disclosure. It is a manufacturing firm based in Dubai, UAE. It has faced major challenges for the last two years due to pandemic outbreak and construction market slowdown after the global economy slow-down. The company is looking to restructure its operations to handle COVID 19 challenges, and to seek possible expansion over the GCC and regional market to counter sharemarket shrink. The company board is considering a major survival call by evaluating the current pandemic situation and considering the market economic forecast over the short and midterm. The board is leaning on the company's leadership to see investigate a major transformational change adding and changing some lines of products, restructuring the operations to suit the Covid 19 demands on its manufacturing facilities and its back up supply chain. It is expecting in-depth transformational strategy from the leadership of the company upon which they will decide to move on with the business or close and re-invest in another market and segment.

\section{Background}

DBS established production facility with a sufficient size necessary in order to penetrate and capture business in multiple market segments both in the local and international markets with a wide range of quality products. Additionally, the facility provided the ability to expand its Research and Development to design, test and expand its products and services range.

\section{Restructure}

The company, like any other SMEs, has undergone a major restructuring due to UAE construction market crisis as result of global recession. DBS has reduced by size of staff and technicians and moved to a smaller yet quite considerable size. On the other hand, DBS has well defined its market share in terms of product portfolio and has recognized many project references throughout its lifetime.

\section{Major Objectives}

Achieving the purpose of restructuring in terms of budgets achievements and streamlines, the organizational procedures depended basically on pursuing the following objectives:

- Maintaining market share in construction segment within UAE market,

- Increasing price competitiveness in the market

- Providing Customers with a Quality Product with On Time Deliveries and continuous After Sales support to ensure Long Term stability with Clients.

- Develop an Aggressive Marketing Plan to penetrate other GCC countries as well as Africa.

- Installation and Implementation of Enterprise Resource Planning software to greatly enhance Internal Process Control Methodologies that will allow for marked improvements.

- Reduction in the cost of sales related to general expenses like salaries, factory expenses, and rents.

Top Management closely manages product development initiatives through the weekly Goal and Objective Reviews with department heads. In approving individual product development initiatives, product development process is followed, which considers not only technical inputs from product line managers but also market customer driven inputs from business development and program managers.

DBS is composed of multiple departments: Accounts, Administration, Projects, Sales \& Estimation, Design, and Production. Departments' heads report directly to General Manager who in turn reports to Board of Directors.

Each department has defined tasks and responsibilities that employees perform. These responsibilities are divided into two categories: primary and secondary. As such, team work is the essence of revealing the required outcomes and smooth execution of projects. Employees come from several different nationalities and diverse cultures.

\section{Challenges Forward}


Since 2018, DBS has been facing multiple challenges as an SME in UAE that have caused its BOD to consider major restructuring or exit market plan. The challenges are summarized as follows:

- Recent Covid 19 pandemic and its implications on company operations, market growth and supply chain sustainability.

- UAE construction market shrink and risks of further decline

- Increasing competition due to its easy entry product types.

- Financial stress on company operations due to increasing gap in cash flow management, and due to increase in financing cost by local banks.

The BOD have delegated to the company management to investigate conducting major change on the organizational level. Based on this investigation, the BOD will study and make a final call on whether to proceed with it or close the whole operations.

\section{DBA Research ( Literature Review / Sensitivity /Participant)}

The above dilemma faced by the board would require in depth study for the company in an attempt to make a major organizational transformation. This transformation would require an exceptional type of leadership that would tackle crisis scenarios.

\section{Effect of Transformational Leadership on SMEs}

Leadership plays an important role in SMEs' innovation and outcomes.

There are several types of leadership styles is the Burns' (1978) theory, which are mainly: transformational and transactional.

Many studies have shown that transformational leadership makes positive and major influence on SMEs' innovation and performance whether is directly or indirect. However, transactional leadership found to have direct positive yet minor effect on SMEs' innovation and performance. (Nungky, Nugraha, \& Sampir, 2020)

Changing environment enhances the importance of leadership in targeting competitive advantage over competitors to boost organizational performance. Effective leadership has a decisive role in the success or failure of organization (Tourish, 2014). It helps to improve the organizational performance in situations where the organization faces a lot of new complications and encounters. Studies show that SMEs faces problems related to leadership styles that reduce organizational performance because they do not identify effective or ineffective leaders (Nazarian, Soares, \& Lottermoser, 2017).

\section{Relativity}

This subject is common to most of the UAE based SME. Conducting such DBA research on as UAE based SME will reveal the way these companies leadership workout its organization change to ensure sustainability of the business.

\section{Participants}

This research should involve multiple levels of participants:

- Company leadership and senior management

- Company employees with confidentiality over feedback

- Company suppliers and any related party to its supply chain

- Company customers and any related party interested in its products

- Other stakeholders whose feedback is needed for the DBA research

- SMEs in UAE leaderships and management

\section{Section 4}

Research Question For The Organizational Problem In Dubai Based Manufacturing SME

Reference to the organizational problem above, a DBA research question formulates to attend the following topic:

How will the organizational management use the latest theories of leadership styles in order to improve the operational performance of the company regain its market share and sustain its operations? 
This major question will be broken down in several parts in order to be able to tackle the problem: What are the major challenges that such leadership style faces in SMEs, particularly in UAE and how can defying these challenges apply on a manufacturing SME based in UAE? Who are the stakeholders that will be mostly affected during this change, positively or negatively? Can this organization change model using this type of leadership be implemented throughout SMEs over UAE and GCC?

Few studies have been tackled in small and medium construction firms in UAE work environment where as many studies selection strategies had concentrated in industries in developed economies (Murrar \& Hammad, 2013, Ghani, 2014). This DBA research will be a strong contribution on three levels:

\section{SMEs in UAE, Manufacturing in particular}

SMEs in UAE have not taken their sufficient quota of research and academic attention although UAE Ministry of Economy estimated that the SME sector forms more than $92 \%$ of the total number of UAE companies and about 52\% of the non-oil gross domestic product (2018 UAE Statistics). Manufacturing UAE sector contributed 14\% to the overall GDP in 2015 (Rahman, 2015), and projected at 20\% by 2021 and 25\% by 2025. 94\% of the manufacturing sector companies are SMEs (Tsetsonis , 2014). Hence, challenges facing UAAE SMEs are the same one the manufacturing sector is facing.

Further to pandemic outbreak in Dec 2019, many financial reports have claimed that over 50\% of UAE based SMEs are facing the dilemma of change or close. On May 2020, CNBC reported that the Chamber surveyed 1,228 CEOs across a range of sectors between April 16 and April 22 2020. Nearly three-quarters of those surveyed were small businesses with fewer than 20 employees. More than two-thirds saw a moderate-to-high risk of going out of business in the coming six months: $27 \%$ said they expected to lose their businesses within the next month, and $43 \%$ expect to go out of business within six.

\section{UAE Economic Outlook Post COVID 19 Outbreak - An un-precedent Crisis}

Short time has passed since COVID-19 outbreak across much of the Middle East including GCC since Feb 2020, where widespread travel restrictions and nationwide lockdowns have resulted in a sharp slowdown in construction activity. In the UAE, the Construction Project Momentum Index has dropped in Q1 2020, falling to 0.12, down from 0.65 in Q4 2019. It is below the average of Middle East and Africa markets of 0.22. In March, the index dropped to 0.05 and declined to 0.07 in May. (Global data, 2021)

More pressure is faced by local organizations since investment action remains weak in the UAE amid the uncertain outlook for international travel, with the retail and hospitality sectors being the most affected (Global data, 2021). The commercial sector in Dubai, the region's most diversified economy, has been hit hard by the disturbance to worldwide travel. Gulf mall owners have put expansion plans on hold as the retail sector continues to struggle amid the absence of tourists. Abu Dhabi's hospitality sector, which has been a centre of events in 2019, attracting tourists and leveraging the sector in the city, will also face the brunt of the contagion, but Expo 2020, which Dubai is to host, also is set to go ahead in 2021 having been postponed for a year due to the pandemic. While fall in demand for tourism due to COVID-19 is temporary, it will take some time to fully recover.

\section{New Leadership types: Shock and Crisis Styles}

Due to the multiple layer challenges that any UAE based SME is facing, research on the multiple and convenient leadership styles as one of the key factors for success will be put to testing in this research.

Traditional leadership styles have tackled transformational changes and linked it to improvement of organizational performance. These theories explain how leadership shapes outcomes under various circumstances.

International companies in GCC are usually characterized by multi-cultural teams, and the leadership style is normally a mix of democratic and authoritarian (Alnasseri et al., 2013), as to be able to cope with people with different cultures.

'Leadership and management style' comes second after 'financial incentives' as contrary to other reports in developed countries where the 'recognition 'ranks first like in Greece (Salonitis \& Tsinopoulos, 2016) as well as Italy (Staudacher \& Tantardini, 2007). This result has its roots in the fact that the wide majority of the manufacturing sector and SMEs hire expatriates from other less-developed and non-Arabic countries 
who are less rewarded (Abi-Raad, 2019). These findings urge the need to find new leadership styles that can concur with crisis level that UAE SMEs currently facing.

\section{Section5}

\section{Stages of The Reaearch Process for Addressing The Research Question}

A research problem is a statement which clearly identifies that issue or situation to be studied (EasterbySmith et al, 2008).

To metaphorize the research concept, Easterby had unfolded the process as tree elements starting from the roots, trunk and branches, leaves and up to the fruit. Roots stand for particular disciplines and past researches experience, thus forming the basis of the design and methods. Trunk stands or the strength and the shape of the tree where it is subdivided into rings, inner for ontology, second for epistemology, third for methodology, and outer for methods and techniques. As in the tree, the three inner rings cannot be shown for the external observer but they constitute major element in the research process. (Easterby-Smith et al, 2008), Refer Figure 5.1

Ontology represents the basic assumptions taken to reflect the reality. Epistemology stands for the ways of enquiring from the world, while methodology is the group of techniques used to make a consistent model.

Going forward, the leaves of the tree take the energy from the sun, and in the research it stands for the data and information that feeds the research. Finally the fruit stands for the report that is made and presented to the community as the final product of the tree / the study. (Easterby-Smith et al, 2008).

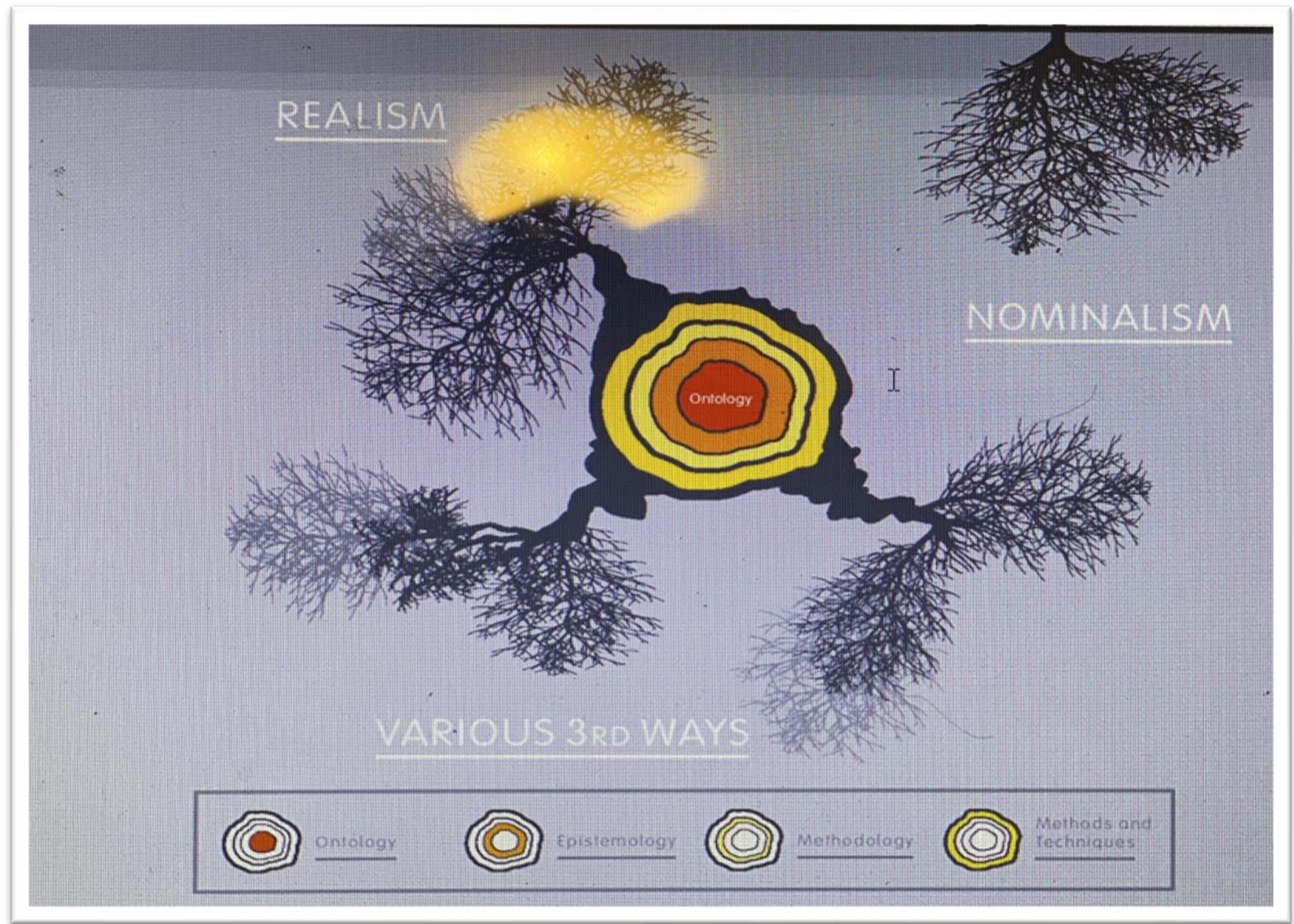

Figure 5.1 A Tree for Management Research

In our case the fruit is our answer to the basic question of the research: how to make the company perform better? And it will be firm stakeholders will be the one who will enjoy eating it.

\section{Four Framework Approach}


As explained above, we will make the blueprint for the tree above in our conduct for research. In fact, we will follow process of research based on Quinlin et al's Four Frameworks approach (Quinlan et al., 2015) that constitute the conceptual, theoretical, methodological, and analytical frameworks.

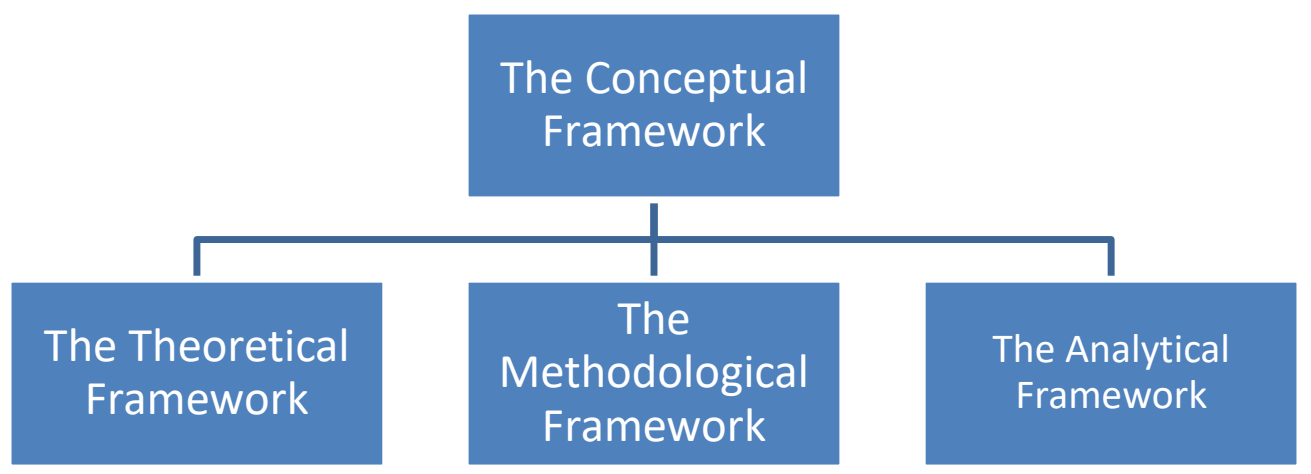

Figure 5.2 Four framework approach

We have described in section 4 the research problem and we will use the above four frameworks in our research for the UAE firm facing existential dilemma.

\section{Conceptual Framework}

Amid Covid pandemic and global economy crisis, the research have to answer basic question on how management will find and use the most convenient leadership style in order to improve the operational performance of the firm. This challenge imposes a management research that approaches leadership theories and organizational changes as well as SME particularity in relation to other type of large firms. It also imposes to take the cultural background of being located in UAE as a diverse business community interrelated with wide global network and unconventional high level governmental leadership. Answering the major question will have to address below sub-questions:

1. How this leadership will apply the above concept in regaining its market share and sustaining its supply chain?

2. What are the challenges that leadership in UAE SMEs face in such organizational transformation and how it will counter them?

3. Who are the stakeholders that will be mostly affected during this change, positively or negatively?

4. Can this organizational transformation using Shock leadership be used as a model to be implemented throughout SMEs over UAE and GCC?

\section{Theoretical Framework}

Study first needs to define certain concepts and assumptions. Organizational transformation is a process where leadership style plays a major role in. In normal times, change would be to enhance certain type of the organization or as a whole considering limited factors that cause such motivation for change. However, when we approach crisis situation and approach shock leadership style, the research process then have to consider multiple theories and must frame the crisis on all levels. Extreme context happening on a wide scale generates a crisis environment where several extreme events occur that exceed the organization's capacity to prevent and result in an extensive and intolerable magnitude of physical, psychological, or material consequences to - or in close physical or psycho-social proximity to - organization members.

Second, organizational changes during pandemics and amid global slowdown need to be conceptualized throughout crisis and extreme conditions scenarios. In this sense, conventional leadership theories will be critically analysed versus new global, cross cultural shock leadership styles. Literature will be narrowed down to effect of leadership on SMEs and their decisive role in success or failures of firm changes during such conditions.

\section{Methodolgical Framework}

Research methodology should follow systemic and scientific rigorous process.

First, general initial information should be gathered in order to acquire a more specific sense of the research problem in numbers. 
Further to above, theory should be defined based on the research question that is stipulated in section 3 . This hypothesis will consider the literature review discussed in earlier part about firm change using specific type of leadership style. Based on this, hypothesis will be formulated in order to prove or decline.

Moving on, data need to be collected in qualitative and quantitative methods to cover various crisis contexts in terms of financial numbers, employees' turnover, and customer satisfaction. Secondly, action research will be made using the leadership theories for organizational transformation. This will be put to test on the firm under crisis to check its outcome on different stakeholders. A comparison will be made among other SME firms in UAE where other models of leadership styles have been used.

Data analysis will be run over for what have been gathered and incorporated. Conclusions will be drawn based on the projected outcomes and mitigations schemes. The research is not aiming at developing a new theory for leadership, but rather uses the mix of styles in order to approach the optimum organizational changes in a crisis and extreme contexts.

\section{Analytical Framework}

Based on the data and information collected during the research study, the organization should be put on a course of transformation scenario using the leadership style that best would lift the company from the disintegrated scenario that they face to a survival mode level and then into improved performance context. Analysis have to define leadership that attends the following in the organizational transformation:

- Acknowledging the Crisis context and identifying its factors

- Bypass the fear of change

- Checks the true north of the firm and tackles the most imminent issues.

- Considers diversity and cross cultural transformation

- $\quad$ Working on KPIs

- Discipline

Further to implementation of the transformation led by the mix of leadership styles, a formula would be deduced in order to verify its applicability to other SMEs and similar firms in UAE. This will be derived from collection of information from representative sample of SMEs in UAE where they had success stories on their transformational level during the last two years

\section{Section6}

\section{Ethical Aspect Of The Research Introduction}

Discussion on ethics in management research is taking deeper dynamics and variety as management research evolves. Today a widening replication taking place in both natural and social sciences surrounding the thoughts of researchers during research who are experiencing ethical dilemmas. As such research ethics cannot be narrowed down to misconduct such as falsification or plagiarism1 (Galewicz 2009:48). Therefore, more attention is paid to general standards of conduct and subjects more directly related to conducting research.

Ethical discussions in the field of social sciences are the generator of contemporary social developments caused by exponential advancement of technology. Internet has become a major global resource which forces qualitative research to address issue of data archiving and its boundaries. The person has to has to have now the guarantee from the researcher is to secure anonymity, yet this is frequently becomes less controllable. Internet also acts as data storage place where empirical data is stored for personal use. Everything now is stores in our computers, iPads, and clouds.

Modern sciences ethical theories started with the positivist that allows all means in the pursue of knowledge and development of science (Wawrzyniak 2005:62). The Enlightenment tradition assumed that the multiplication of the wealth of knowledge is an absolute assumption (Rancew-Sikora and Cymbrowski 2016:27). Rationality is the fundamental of Western society (Kincaid, Dupré, and Wylie 2007:4). As alternative approach, post-humanist ethics had shown and changed the discussion from power relationship toward the 'world-making' powers of practices of inquiry" (Mauthner 2019:670-671). New theories of Ethics was presented by Denzin and Giardina (2007:18) who proposed alternative ethics: "the purpose of research is not generation of new knowledge but involving the enhancement of morals, a commitment to practice, justice, an ethic of resistance, and a performative pedagogy that resists oppression." 
A major portion of UAE business and government organizations have Islamic cultural background in approaching ethical issues, according to the (a study by the Gulf Centre for Excellence in Ethics (Carvalho, 2001). Yet, UAE firms are extremely diverse where there are more than 150 nationalities working in local and international companies. This diversity imposes different cultures and backgrounds that would impact ethical perspectives. Subjects related to gender equality, ethnical discrimination, and CSR are examples for differences in ethical approaches within organizations. Meanwhile, many of UAE firms have no written codes of ethics or any formal training programs to guide the ethical conduct (McKechnie et al., 2007). Ethical conduct in such DBA researches thus becomes of great significance.

\section{Responsibility during the Research}

Research marks immense responsibility on the researcher attending participants and subjects that could have major effect on them. This research marks the first of a kind that the organization undergoes in journey. In general, DBA researches on SMEs in UAE is a developing field in an emerging market that still need to be approached in a spirit of ethical responsibility. Except for Dubai Scientific Research Ethics committee (DSREC) that handles the ethical standards during conduct of medical research and Knowledge and Human Development Authority (KHDA) that handles Educational Firms, there are no official ethical committees/authorities to monitor ethical conduct for businesses and private organizations. UAE SMEs are relatively young in age and would lack expertise in the concepts of good governance and recent Ethical practices in business researches. In fact, it is rarely found that there is any type of ethical committees that monitor for ethical practices during management researches. This highlights further responsibility on DBA students to follow an interpersonal responsibility towards the ethical aspect of the research.

\section{Integrity of the Research}

It is of no use to conduct a research that would deviate from the real dilemmas and accurate factors that are necessitating a DBA research for an SME in UAE. Integrity of the research is an objective necessity for its ability to approach the research question and conclude on its answer.

Integrity has to consider that the right participants are asked the right questions. Honesty towards information and avoiding any advantage taking from the participant, respect for their opinions and allowing them to share their doubts, and keeping positive commitments that are made will be a major part of the research process.

\section{Respect of Participants Rights and Dignity}

The participant is an interactive element in the research and "there is no separation between finding out the world and ensuring that no harm is done in the course of such an investigation. Knowledge production is an inherently ethical matter" (Mauthner 2019:680).

During conducting the research, it is highly important that participants are aware of their rights before conducting the research. Confidentiality, consent, and sensitivity of cultural backgrounds need be addressed during conduction of research whether filling up information or direct interviewing.

\section{Conclusion}

Management research is evolving practical field that businesses have additional need for it to counter modern challenges facing firms and organizations. DBA specialization becomes imminent requirement to help UAE SMEs for solving managerial problems and providing scientific solutions for management dilemmas.

We have discussed in this paper how such management research will approach one of Dubai based firm an existential question and the road map to offer a solution that is based on leadership theories that have been progressing over the past years.

This report has defined the concepts of management research by reviewing the different type of its theories and schools. As a major management topic, the report has focused on leadership relation to organizational transformation where it have gone through the chronologically and type-wise leadership styles that affects firm course of change.

Further to that, this paper has stipulated the research problem of the UAE firm as an SME that need to face transformation using the best leadership option.

We described the frameworks that will be used to analyze the problem and put it on the path to solve. 
Eventually, we have explained the ethical dimensions of such research and the concerns that would be facing during such research. SMEs in UAE ethical standards are reviewed and we have drawn ethical guidelines to following during the DBA study.

\section{References}

1. Alefari, M., Almanei, M. \& Salonitis, K. 2020, "Lean manufacturing, leadership and employees: the case of UAE SME manufacturing companies", Production \& Manufacturing Research, vol. 8, no. 1, pp. 222-243.

2. Augier, M. 2004, "March'ing towards "a behavioral theory of the firm": James G. March and the early evolution of behavioral organization theory", Management Decision, vol. 42, no. 10, pp. 1257 1268.

3. Bhattacherjee, A., (2012) Social Science Research: Principles, Methods, and Practices, $2^{\text {nd }}$ Edition

4. Bochman, D.J. \& Kroth, M. 2010, "Immunity to transformational learning and change", The Learning Organization, vol. 17, no. 4, pp. 328-342.

5. Bonsu, S. \& Twum-Danso, E. 2018, "Leadership Style in the Global Economy: A Focus on CrossCultural and Transformational Leadership", Journal of Marketing and Management, vol. 9, no. 2, pp. 37-52.

6. Easterby-Smith, M., Thorpe, R., Jackson, P. and Lowe, A., (2008). Management Research, $3^{\text {rd }}$ Edition London.

7. Fayol, H. (1949). General and industrial management. London: Sir Isaac Pitman \& Sons, Ltd.

8. Fayol, H. (1917); Administration Industrielle et Générale : prévoyance, organisation, commandment, coordination, contrôle, Paris: H. Dunod et E. Pinat.

9. Fragouli, E. 2020, A critical examination of the interaction of crisis leadership \& corporate reputation, Centre for Business \& Economic Research, London.

10. Heinsman, H., Annebel HB, d. H., Koopman, P. L., \& van Muijen, J.,J. (2008). Commitment, control, and the use of competency management. Personnel Review, 37(6), 609-628.

11. Hisham, H.H. 2019, "The riddle of self-centered leadership in Arab organizations: a measurement scale: MRN", Management Research Review, vol. 42, no. 4, pp. 430-459.

12. Hitt, Michael A, Middle Mist, R Dennis and Mathis, Robert L. (1979). Effective Management: New York : West Publishing Company

13. Greenwood, R.A. 2002, "The Essential Drucker", Journal of Leadership \& Organizational Studies, vol. 8, no. 4, pp. 101-103.

14. Global Data, Q1 2021, Construction in UAE, Key Trends and Opportunities to 2025, Q1 2021 Update, Available on WWW.GLOBALDATA.COM

15. Kaźmierska, K. 2020, "Ethical Aspects of Social Research: Old Concerns in the Face of New Challenges and Paradoxes. A Reflection from the Field of Biographical Method", Qualitative Sociology Review, vol. 16, no. 3.

16. Kegan, R. (1982) The Evolving Self. Problem and Process in Human Development. Boston, MA: Harvard Business Review Press.

17. Kegan, R. (2003). In over our heads: the mental demands of modern life. Cambridge, MA: Harvard University Press.

18. Kegan, Robert; Lahey, Lisa Laskow (2009). Immunity to change: how to overcome it and unlock potential in yourself and your organization. Boston: Harvard Business Press. ISBN 9780787963781. OCLC 44972130

19. Kitana, A. 2016, "Overview of The managerial Thoughts and Theories from the History: Classical Management Theory to Modern Management Theory", Indian Journal of Management Science, vol. 6, no. 1 , pp. 16-21.

20. Koontz H, The Management Theory Jungle, Academy of Management Journal, (1961). 4 (3), 174 188

21. Kuhnert, K.W. \& Lewis, P. 1987, "Transactional and Transformational Leadership: A Constructive/Developmental Analysis", Academy of Management. The Academy of Management Review, vol. 12, no. 4, pp. 648.

22. Lagowska, U., Sobral, F. \& Furtado, L.M.G.P. 2020, "Leadership under Crises: A Research Agenda for the Post-COVID-19 Era", Brazilian Administration Review, vol. 17, no. 2, pp. 1-5.

23. Mayo, E. (1933). The human problem of an industrial civilization. New York, NY: Macmillan. 
24. McGregor, D. (1960). The human side of enterprise. New York, NY: McGraw-Hill.

25. Nungky, V.F., Nugraha, A. \& Sampir, A.S. 2020, "Effect of transformational and transactional leadership on SMEs in Indonesia", Problems and Perspectives in Management, vol. 18, no. 3, pp. 415425.

26. Omodan, B.I., Tsotetsi, C.T. \& Dube, B. 2020, "Analysis of human relations theory of management: A quest to re-enact people's management towards peace in university system", SA Journal of Human Resource Management, vol. 18.

27. Reiche, B.S., Bird, A., Mendenhall, M.E. \& Osland, J.S. 2017, "Contextualizing leadership: a typology of global leadership roles", Journal of International Business Studies, vol. 48, no. 5, pp. 552-572.

28. The SAGE Handbook of Organization Studies, edited by Stewart R Clegg, Cynthia Hardy, Tom Lawrence, Walter R Nord, 2006, $2^{\text {nd }}$ edition, pages $254-260$

29. The SAGE Handbook of Management Learning, Education and Development, edited by Steven $\mathbf{J}$ Armstrong, Cynthia V Fukami, 2009, page 42-45

30. Scott Thurm and Joann S. Lublin 2005, Theory \& Practice: Peter Drucker's Legacy Includes Simple Advice: It's All About the People, Eastern edition edn, New York, N.Y.

31. Shufutinsky, Anton, PhD, DHSc,M.P.H., R.E.H.S., Deporres, D., EdD., Long, Bena,PhD., M.S.M. \& Sibel, James R,PhD., M.A. 2020, "SHOCK LEADERSHIP DEVELOPMENT FOR THE MODERN ERA OF PANDEMIC MANAGEMENT AND PREPAREDNESS", International Journal of Organizational Innovation (Online), vol. 13, no. 1, pp. 20-42.

32. "Plotting a path post-Covid for the Middle East's banks", 2020, Euro money,

33. Taylor, F. W. (1911). The principles of scientific management. New York, NY \& London: Harper \& Brothers Publishers. 